\title{
The Impact Of Business Faculty Attire On Student Perceptions And Engagement
}

David L. Carr, Ph.D., University of South Dakota, USA

Angeline M. Lavin, Ph.D., CFA, University of South Dakota, USA

Thomas L. Davies, LL.M. CPA, University of South Dakota, USA

\begin{abstract}
Certainly not a new phenomenon, professors continue to strive to discover the magic elixir that will cause all students to become active participants in the learning process. It seems logical that if students find a topic interesting or pertinent to their career objectives, they will tend to take a more active role in a course. Perhaps as reasonable to assume, if instructors are engaging and have the respect of the class, students will naturally put forth more effort to master the material. Prior studies have also shown that certain pedagogical devices and innovations, such as the usage of presentation technology, can positively impact student motivation. This study explored whether something as basic as the professor's attire could also have a motivating effect on student perceptions and behavior in a college classroom setting. This paper summarizes the results of a survey pertaining to faculty dress that was administered to students enrolled in selected business courses at a mid-sized Midwestern university. Students were asked their opinion of whether the professional or unprofessional dress of the instructor would conceivably impact their own learning and effort. The survey results show that, in general, students perceive professional dress positively, and adjust their behavior accordingly.
\end{abstract}

Keywords: Student engagement, student effort, student perceptions, faculty attire, professional dress

\section{INTRODUCTION}

(๑)

ver the years, educational researchers have written about many techniques that academicians can use to better engage their students in active learning and encourage them to participate in the educational process. In 1987 Chickering and Gamson published The Seven Principles for Good Practice in Undergraduate Education, which has been widely distributed and quite influential in bringing attention to pedagogies that encourage student engagement. In essence, the authors believe that what instructors do, in addition to what they teach, can encourage student-faculty contact, cooperation among students, and active learning. Likewise, Astin's large-scale correlation study of 27,000 students attending over 300 institutions found that two environmental factors, specifically interaction among students and interaction between faculty and students, influenced more general education outcomes than any other environmental variables, including curriculum content. These results suggest that how students approach their education and how the faculty actually deliver the material is at least as important, and perhaps more important, than the formal curriculum or content of a course when it comes to student learning or at least perceived learning. In other words, what the student believes he or she is learning can be crucial to the educational process and numerous studies have undertaken to identify factors that can influence learning.

There may be disagreement among faculty about whether, in fact, the "how" (i.e., medium) does supersede the "what" (i.e., message) in importance as the Astin study suggests. However, given the emphasis that many schools place on both active learning as well as excellent teaching evaluations, it may be safe to assume that many faculty focus at least some attention on the success of content delivery and all factors that potentially influence student receptiveness. Although the motivation of individual faculty members for attempting to improve content delivery may vary, the ultimate goal is to engage the students and enable them to learn more. In addition, there may 
also be an optimistic belief by the faculty member that his or her teaching evaluations will improve if the students are more receptive to the delivery medium and the total classroom experience.

The goal of this research is to investigate whether something as simple and seemingly superficial as the instructor's choice of attire can have an impact on student perceived learning and effort. Clearly, a professor's ability to teach as well as to influence students is not limited to what he or she says. According to Mehrabian (1968), only a small portion, i.e., less than $10 \%$, of a message is actually sent through words, and when verbal and nonverbal messages conflict, the latter usually prevails (Rice, 1977). Indeed, actions and behavior can speak louder than words, or in other words, how something is conveyed can be more influential than what is being conveyed. What professors do, how they behave and even how they look may at times be as significant than what they discuss in the classroom, at least when it comes to what the students gain from the experience.

\section{PRIOR RESEARCH}

The study of what makes a college teacher successful is not a new phenomenon and remains an interest to many academic researchers. Witcher, Onquegbuzie, Collins, Filer, Wiedmaier, and Moore (2003) suggest that students believe that effective college teaching encompasses the following nine characteristics, listed in order of importance: (1) student-centered; (2) knowledgeable about the subject matter; (3) professional; (4) enthusiastic about teaching ; (5) effective at communication; (6) accessible; (7) competent at instruction; (8) fair and respectful; and (9) provider of adequate performance feedback. . So one may ask, does an instructor's choice of professional attire assist him or her in better achieving any of these nine characteristics? At first glance, one might conclude that the image the instructor portrays pertains mostly to his or her professionalism. Yet attire may have a more expansive effect given the interrelation of the characteristics. Perhaps faculty dress sends a much broader message than what many might initially think.

Desmond Morris (1977) postulated that "it is impossible to wear clothes without transmitting social signals. Every costume tells a story, often a very subtle one, about its wearer." Past studies generally have found that instructors who dress more formally are perceived as being knowledgeable, organized and well-prepared while more casually dressed instructors are generally perceived as being friendly, flexible and sympathetic (Rollman, 1980).

Certainly, the style of dress can convey status and power. A 1977 article by Rollman found that a professor who dressed in a casual style (jeans, sports shirt, and tennis shoes) was perceived as having less status than when he dressed in a formal suit and tie. Formal dress is frequently perceived by the general public as having more status because of repeated exposure to professionals wearing suits.

Molloy $(1975,1977)$ postulated that clothing impacts or influences four kinds of judgments, including credibility, likeability, interpersonal attractiveness and dominance, and thus acts as a primary impression management tool. Impression management involves a person's "conscious attempt to exercise conscious control over selected communicative behaviors and cues - particularly nonverbal cues, for purposes of making a desired impression" (Leathers, 1992). Lukavsky, Butler and Harden (1995) studied the impact of attire on the personal characteristics of approachability, inflexibility, and respect. They found significant differences in student perceptions of those three characteristics based on whether the instructor was formally or informally dressed. The instructor who dressed informally was rated most approachable and flexible but at the same time commanded the least respect.

A few studies have been reported as to various aspects of dress in an academic setting, and the overall conclusion that can be reached is that formal or professional attire is most positively perceived by students (e.g., Harris et al., 1983; Bassett, 1979). A study of 318 college students by Kwon and Johnson-Hillery (1998) indicated that the students rated individuals who were dressed in formal business attire more positively on a variety of occupational attributes (such as knowledgeable, competent, credible, businesslike, responsible, trustworthy, and efficient) then individuals who were dressed either semi-formally or informally. Sebastian and Bristow (2008) found that students attribute more expertise to professors who are dressed formally, but they also ranked formally dressed professors lower than casually dressed professors in terms of likeability. 
In light of the current debate as to what clothing is acceptable in a particular setting (e.g., the office or during interviews), what is worn by the faculty member may be of considerable significance as to the message being sent to students. Business educators are not only expected to impart knowledge in their classrooms but can take on the added responsibility of serving as role models for the students, especially traditional students who have limited exposure to the corporate environment. Therefore, educators must pay attention to the substance of what they teach as well as to how the image that they convey influences those around them (Scott, O'Neal, and Cheatham, 1994). Although the topic of attire may not seem significant to a scientific scholar, it is of utmost concern to the business practitioner. Consider a recent article that was published in the Wall Street Journal on April 17, 2008 entitled "Business Casual: All Business, Never Casual." The article discusses the issues and uncertainties that accompany the modern "business casual" trend in the corporate world and concludes, "Traditional business dress is seen as a uniform .... It simplifies decision-making and makes hierarchies easy to read." The article concludes with the statement, "The whole idea of dressing for business is to put a suite of armor around the body." Would professors also benefit from heeding this advice when it comes to motivating students?

\section{PRESENT STUDY}

Students taking selected business classes in a mid-sized Midwestern university were asked to participate in a research study with the purpose of assessing how a professor's appearance in the classroom might impact the effort that students put forth in the classroom, as well as their learning. As part of the project, students were reminded that the instructor's attire was a matter of personal choice which depended upon multiple factors such as classroom conditions (e.g., heating, cooling and ventilation), the class setting (e.g., evening class, length of class session), delivery mode (e.g., face to face versus distance) and his or her individual preferences and comfort.

Students in the chosen classes were asked for their opinion of how the professor's dress might impact their own behavior. Students were informed that the study was not meant to be an evaluation of a particular instructor, but how the appearance of a hypothetical professor might impact their own effort. Survey questions were patterned after three different student evaluation forms previously or currently being used at the authors' institution, including a form created and used by all regental public institutions within the state, the student instructional report II (i.e., SIR II), and the IDEA Diagnostic Form Report.

The survey instrument consisted of several sections. The first section consisted of 15 questions, broken down into several groups of inquiries, which were substantive in nature. Students were initially asked how the instructor's attire would influence their overall appreciation for the course, including the instructor's effort, the importance of the material, the amount they learned, their desire to take additional classes from the instructor or in the subject area, and their respect for the instructor. The second group of questions asked how the professor's appearance would impact their own engagement in the classroom, including attendance, participation, attentiveness, and willingness to ask questions. The third group asked how the professor's appearance might affect their own engagement outside the classroom, including preparation for class, time spent studying, and willingness to ask questions outside of class. This part of the survey also contained two questions on how the professor's usual attire would impact the student's overall evaluation of the course and of the instructor. Specific questions were as follows:

\section{Overall Appreciation}

- $\quad$ The amount you learn from class.

- Your appreciation for the instructor's effort.

- Your appreciation for the importance of the material.

- Your desire to take additional classes from the particular instructor.

- $\quad$ Your desire to take additional classes in the subject matter.

- $\quad$ The level of your respect for the instructor.

Personal Engagement in the Classroom

- $\quad$ Your attentiveness in class.

- Your level of participation in class discussions. 
- $\quad$ Your overall attendance for the course.

- $\quad$ Your willingness to ask the instructor questions during class.

Out of Class Engagement

- $\quad$ The level of your preparation for each class session.

- $\quad$ The amount of time you study for exams, etc.

- Your willingness to ask the instructor questions outside of class.

Course and Instructor Evaluation

- Your overall evaluation of a course.

- Your overall evaluation of an instructor.

The second section of the survey consisted of multiple demographic questions. Students were asked whether they were graduate or undergraduate students, their program of study or major, and their year in school (e.g., freshman, sophomore, etc.) as well as their grade point average, gender, age, race, and personality type. In addition, students were asked about their background and upbringing (white or blue collar), role models (white or blue collar, or other), whether they were from a rural or urban area, the extent of their business/professional work experience, and whether they planned on pursuing/continuing a business/professional career.

Two versions of the survey were administered. One version asked students to assume the professor's attire and appearance was professional while the alternative assumed unprofessional dress. The terms "professional" and "unprofessional" were not defined or described, as students were intentionally left to arrive at their own interpretation. With respect to the substantive questions, all responses were based on a five point scale, with " 1 " being significantly positive, " 2 " being somewhat positive, " 3 " being no difference, " 4 " being somewhat negative, and " 5 " being significantly negative.

Thirteen members of the faculty, including two of the authors administered the survey in their classes. The selected faculty were chosen because of their discipline and gender in order to provide a cross-section of courses being evaluated. Classes chosen included those at the 100 (first year), 200 (second year), 300 (third year), 400 (fourth year) and graduate (700) level. In addition, courses were selected from almost all majors offered by the school including accounting, business law and legal environment, economics, management/organizational behavior, marketing and strategy at the undergraduate level as well as from the MBA (finance and production) and MPA (Master of Professional Accountancy) programs. The survey was administered in seventeen classes, including multiple sections of several of the courses offered on the university's main campus. In addition, several off-campus face-to-face classes were chosen, including one that was part of the MBA cohort program.

The survey was administered near the midpoint of the term. Enrollment in the sections evaluated totaled approximately 680 students, including some students who were enrolled in more than one of the classes included in the sample. However, students were asked to complete the survey only once, since it was not designed to be class or course dependent. Faculty were free to either set aside class time to allow for completion of the survey or have students complete the questionnaire outside of class and return it later via an anonymous collection box. Students did not receive extra credit for completing the survey. In total, approximately 450 usable surveys were completed and returned.

\section{RESULTS}

As previously mentioned, two versions of the survey were administered. Questions included in each version were identical; however, students receiving one version of the questionnaire were asked to assume the hypothetical professor wore professional attire and in the second version, unprofessional attire. The surveys were placed in alternating order prior to their random distribution. In total, 219 usable "professional" and 227 usable "unprofessional" surveys were collected. Survey respondents were asked to answer several demographic questions including gender, age, race, year in school, major, personality type (competitive or easy going), status (traditional or non-traditional), role models (white collar, blue collar, or other), background (rural or urban), work experience, and 
whether they were planning on a business career. Respondent demographic characteristics for the two surveys were similar. The demographic data is available upon request.

\section{Table 1}

Descriptive Statistics and Frequency Distributions for the Surveys on "PROFESSIONAL" attire

\begin{tabular}{|c|c|c|c|c|c|c|c|c|c|c|}
\hline 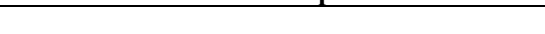 & & & & Std & Pos & & Neu & & Negative & \\
\hline & Mean & Median & Mode & Dev & 1 & 2 & 3 & 4 & 5 & N/A \\
\hline \multicolumn{11}{|c|}{ An Overall Appreciation } \\
\hline The amount you learn from class. & 2.47 & 3 & 3 & 0.83 & 35 & 57 & 115 & 1 & 1 & 1 \\
\hline Your appreciation for the instructor's effort. & 2.13 & 2 & 2 & 0.92 & 57 & 93 & 57 & 5 & 0 & 0 \\
\hline $\begin{array}{l}\text { Your appreciation for the importance of the } \\
\text { material. }\end{array}$ & 2.40 & 2 & 3 & 0.83 & 34 & 75 & 97 & 2 & 2 & 2 \\
\hline $\begin{array}{l}\text { Your desire to take additional classes from the } \\
\text { instructor. }\end{array}$ & 2.38 & 3 & 3 & 0.91 & 45 & 62 & 97 & 3 & 1 & 1 \\
\hline $\begin{array}{l}\text { Your desire to take additional classes in the } \\
\text { subject matter. }\end{array}$ & 2.59 & 2 & 1 & 0.85 & 27 & 56 & 121 & 5 & 0 & 0 \\
\hline The level of your respect for the instructor. & 1.85 & 2 & 1 & 0.89 & 90 & 84 & 33 & 11 & 1 & 0 \\
\hline \multicolumn{11}{|c|}{ Personal Engagement in the Classroom } \\
\hline Your attentiveness in class. & 2.32 & 2 & 2 & 0.90 & 41 & 86 & 78 & 9 & 5 & 0 \\
\hline Your level of participation in class discussions. & 2.68 & 3 & 3 & 0.79 & 17 & 60 & 121 & 18 & 3 & 0 \\
\hline Your overall attendance for the class. & 2.42 & 3 & 3 & 0.93 & 49 & 45 & 113 & 9 & 3 & 0 \\
\hline $\begin{array}{l}\text { Your willingness to ask the instructor questions } \\
\text { during class. }\end{array}$ & 2.67 & 3 & 3 & 0.83 & 14 & 75 & 104 & 19 & 6 & 1 \\
\hline \multicolumn{11}{|c|}{ Out of Class Engagement } \\
\hline $\begin{array}{l}\text { The level of your preparation for each class } \\
\text { session. }\end{array}$ & 2.32 & 2 & 2 & 0.79 & 33 & 93 & 84 & 8 & 1 & 0 \\
\hline $\begin{array}{l}\text { The amount of time you study for exams and } \\
\text { quizzes. }\end{array}$ & 2.44 & 3 & 3 & 0.85 & 36 & 65 & 106 & 10 & 2 & 0 \\
\hline $\begin{array}{l}\text { Your willingness to ask the instructor questions } \\
\text { outside of class. }\end{array}$ & 2.58 & 3 & 3 & 0.95 & 35 & 54 & 104 & 21 & 5 & 0 \\
\hline \multicolumn{11}{|c|}{ Overall Evaluation } \\
\hline Your overall evaluation of a course. & 2.38 & 2 & 3 & 0.82 & 31 & 87 & 89 & 10 & 2 & 0 \\
\hline Your overall evaluation of an instructor. & 2.08 & 2 & 2 & 0.89 & 61 & 93 & 54 & 8 & 3 & 0 \\
\hline
\end{tabular}

Table 2

Descriptive Statistics and Frequency Distributions for the Surveys on "UNPROFESSIONAL" attire

\begin{tabular}{|c|c|c|c|c|c|c|c|c|c|c|}
\hline & & & & & Pos & & Neutral & & Negative & \\
\hline & Mean & Median & Mode & Std Dev & 1 & 2 & 3 & 4 & 5 & N/A \\
\hline \multicolumn{11}{|c|}{ An Overall Appreciation } \\
\hline The amount you learn from class. & 2.76 & 3 & 3 & 0.84 & 19 & 50 & 125 & 27 & 4 & 2 \\
\hline Your appreciation for the instructor's effort. & 2.87 & 3 & 3 & 1.13 & 30 & 56 & 68 & 56 & 15 & 2 \\
\hline $\begin{array}{l}\text { Your appreciation for the importance of the } \\
\text { material. }\end{array}$ & 2.79 & 2 & 3 & 0.93 & 26 & 44 & 109 & 43 & 3 & 2 \\
\hline $\begin{array}{l}\text { Your desire to take additional classes from the } \\
\text { instructor. }\end{array}$ & 2.91 & 3 & 3 & 1.07 & 25 & 43 & 106 & 29 & 22 & 2 \\
\hline $\begin{array}{l}\text { Your desire to take additional classes in the } \\
\text { subject matter. }\end{array}$ & 2.85 & 3 & 3 & 0.82 & 18 & 35 & 140 & 26 & 6 & 2 \\
\hline The level of your respect for the instructor. & 2.85 & 3 & 3 & 1.22 & 41 & 43 & 69 & 52 & 20 & 2 \\
\hline \multicolumn{11}{|c|}{ Personal Engagement in the Classroom } \\
\hline Your attentiveness in class. & 2.76 & 3 & 3 & 1.04 & 34 & 48 & 87 & 51 & 5 & 2 \\
\hline Your level of participation in class discussions. & 2.74 & 3 & 3 & 0.86 & 21 & 53 & 118 & 29 & 4 & 2 \\
\hline Your overall attendance for the class. & 2.62 & 3 & 3 & 0.98 & 44 & 30 & 125 & 20 & 6 & 2 \\
\hline $\begin{array}{l}\text { Your willingness to ask the instructor questions } \\
\text { during class. }\end{array}$ & 2.69 & 3 & 3 & 0.94 & 44 & 30 & 125 & 20 & 6 & 2 \\
\hline \multicolumn{11}{|c|}{ Out of Class Engagement } \\
\hline $\begin{array}{l}\text { The level of your preparation for each class } \\
\text { session. }\end{array}$ & 2.87 & 3 & 3 & 0.93 & 21 & 46 & 104 & 50 & 4 & 2 \\
\hline $\begin{array}{l}\text { The amount of time you study for exams and } \\
\text { quizzes. }\end{array}$ & 2.72 & 3 & 3 & 0.93 & 28 & 50 & 110 & 32 & 5 & 2 \\
\hline $\begin{array}{l}\text { Your willingness to ask the instructor questions } \\
\text { outside of class. }\end{array}$ & 2.72 & 3 & 3 & 1.01 & 24 & 64 & 101 & 29 & 7 & 2 \\
\hline \multicolumn{11}{|c|}{ Overall Evaluation } \\
\hline Your overall evaluation of a course. & 2.83 & 3 & 3 & 0.93 & 22 & 47 & 110 & 40 & 6 & 2 \\
\hline Your overall evaluation of an instructor. & 2.93 & 3 & 3 & 1.09 & 27 & 46 & 82 & 55 & 15 & 2 \\
\hline
\end{tabular}


Responses to the substantive questions for both the "professional" and "unprofessional" versions of the survey are shown in Tables 1 and 2, respectively. The mean, median, mode and standard deviation are provided for each question, along with a frequency distribution of the number of students who gave each specific response. As mentioned previously, all responses were based on a five point scale, with "1" being significantly positive, "2" being somewhat positive, " 3 " being no difference, " 4 " being somewhat negative, and "5" being significantly negative. The mean responses to each question were tested against a neutral response, and in all cases were determined to be significantly different than neutral.

An examination of the two tables shows that the mean response for the "professional" version of the survey is less than the comparable mean for the "unprofessional" version of the questionnaire for each of the 15 substantive questions. On the surface, this finding suggests that students tend to appreciate the course more and are more engaged both in and outside the classroom when the professor's attire is professional compared to a less professional, more casual instructor appearance. Consistent with previously discussed findings, a majority of students also indicated that they would tend to rate the course and the instructor more highly when the professor's attire is professional.

In order to statistically validate the results of this study, large sample one-tailed t-tests on the means were performed for each question on the two surveys. The results are shown in Table 3. The null hypothesis assumed that the mean response for the professional version of the survey would exceed that of the unprofessional version of the survey, or in other words, the difference between the professional and unprofessional mean response would be positive. If true, this outcome would suggest that students responding to the professional survey would rate the professional's instructional trait in question less positively (i.e., more negatively, given the response choice ordering) than would those responding to the unprofessional version of the survey. The alternative hypothesis assumed that the mean response of the professional version of the survey would be less than that of the unprofessional version of the survey, or that the difference between the professional and unprofessional means would be negative. If the results suggested that the difference in means is negative, it would indicate that students responding to the professional survey rate the professional attire and appearance of the instructor more positively (i.e., less negatively, given the response choice ordering) than those who completed the unprofessional version of the survey.

\begin{tabular}{|c|c|c|c|c|}
\hline \multicolumn{5}{|c|}{$\begin{array}{c}\text { Table } 3 \\
\text { t-statistics for differences in means tests } \\
H_{0}: \text { Mean }(p)-\operatorname{Mean}(u) \geq 0 ; H_{a}: \text { Mean }(p)-\text { Mean }(u)<0\end{array}$} \\
\hline & Mean & d.f. & $\begin{array}{l}\text { Prob } \\
\text { T> “t”" }\end{array}$ & $\begin{array}{l}\text { Critical } \\
\text { "t" }\end{array}$ \\
\hline \multicolumn{5}{|l|}{ An Overall Appreciation } \\
\hline The amount you learn from class. & -3.68 & 441 & 0.00012941 & 1.648 \\
\hline Your appreciation for the instructor's effort. & -7.51 & 428 & $1.70019 \mathrm{E}-13$ & 1.648 \\
\hline Your appreciation for the importance of the material. & -4.65 & 438 & $2.18233 \mathrm{E}-06$ & 1.648 \\
\hline Your desire to take additional classes from the instructor. & -5.60 & 434 & $1.86675 \mathrm{E}-08$ & 1.648 \\
\hline Your desire to take additional classes in the subject matter. & -3.33 & 441 & 0.000474513 & 1.648 \\
\hline The level of your respect for the instructor. & -9.89 & 409 & 4.1157E-21 & 1.649 \\
\hline \multicolumn{5}{|l|}{ Personal Engagement in the Classroom } \\
\hline Your attentiveness in class. & -4.72 & 436 & $1.55801 \mathrm{E}-06$ & 1.648 \\
\hline Your level of participation in class discussions. & -0.79 & 440 & 0.215433923 & 1.648 \\
\hline Your overall attendance for the class. & -2.23 & 442 & 0.013138552 & 1.648 \\
\hline Your willingness to ask the instructor questions during class. & -0.28 & 438 & 0.389440502 & 1.648 \\
\hline \multicolumn{5}{|l|}{ Out of Class Engagement } \\
\hline The level of your preparation for each class session. & -6.71 & 434 & $3.0863 \mathrm{E}-11$ & 1.648 \\
\hline The amount of time you study for exams and quizzes. & -3.27 & 440 & 0.000582959 & 1.648 \\
\hline $\begin{array}{l}\text { Your willingness to ask the instructor questions outside of } \\
\text { class. }\end{array}$ & -1.56 & 441 & 0.060243696 & 1.648 \\
\hline \multicolumn{5}{|l|}{ Overall Evaluation } \\
\hline Your overall evaluation of a course. & -5.35 & 438 & 7.2197E-08 & 1.648 \\
\hline Your overall evaluation of an instructor. & -9.01 & 429 & $3.51433 \mathrm{E}-18$ & 1.648 \\
\hline
\end{tabular}


As Table 3 illustrates, the null hypothesis that the means for the professional survey questions are greater (more negative or less positive) than the means for the unprofessional survey questions can be rejected for each of the questions at a $95 \%$ level of confidence. Further, the t-statistic for all questions is negative, which indicates that the mean responses for the professional survey are actually lower (less negative or more positive) than the mean responses for the unprofessional survey. Therefore, these results suggest that the instructor's professional attire has a positive impact on student engagement as well as their appreciation of the course.

Table 4 provides a comparison of the mean responses and resultant rankings of the questions in each survey. (For instance, for the last question, "Your overall evaluation of an instructor," the mean response for the professional survey was 2.08 , while the mean response for the unprofessional was 2.93 . If the mean responses were ranked from lowest to highest (i.e., most positive impact to most negative impact on student perceptions), "Your overall evaluation of an instructor," would be ranked second out of the 15 questions included in the professional survey, and ranked fifteenth (last) on the unprofessional survey. It is interesting to note that rankings between the two surveys are close to being inverted for several of the questions, particularly ones that have to do with the students' perception of the instructor:

\section{Most Positive (Lowest Mean) Response - Professional Survey}

Your overall evaluation of an instructor.

Your appreciation for the instructor's effort.

The level of your respect for the instructor.

\section{Most Positive (Lowest Mean) Response - Unprofessional Survey}

Your level of participation in class discussions.

Your willingness to ask the instructor questions during class.

Your willingness to ask the instructor questions outside of class.

The first question had nearly the lowest mean response (most positive) on the professional survey but the highest mean (least positive) of the 15 questions on the unprofessional version of the survey. The second and third questions were similar, showing very positive responses for the professional survey and less positive responses for the unprofessional survey. The last three questions were just the opposite with some of the least positive responses on the professional survey and the most positive responses on the unprofessional survey.

Overall, the survey responses seem to suggest that students feel more comfortable approaching instructors with questions both inside and outside the classroom and participating in class discussion when the professor is not dressed as professionally. The students also indicated that unprofessional dress has the most positive impact (lowest mean) on students' overall attendance for the course. On the other hand, the students seemed to appreciate professionally dressed instructors more and suggested that they would be more likely to evaluate the course and the instructor highly if the instructor dresses more formally.

It is also interesting to note that while the professional attire of the instructor had a positive impact on the students' overall evaluation of the instructor ( 2.08 mean response for the professional survey version), there was a more neutral, albeit still positive impact on the student's perception of the course (2.38 mean response on the professional survey). However, with respect to the unprofessional survey, students rated both the instructor and course negatively in relative terms; a 2.93 mean was reported for the overall evaluation of the instructor, and a 2.83 mean was reported for the overall evaluation of the course. These two questions were ranked $15^{\text {th }}$ (last) and $9^{\text {th }}$, respectively, out of the questions contained in the unprofessional survey.

\section{CONCLUSION}

While the debate continues as to what factors can increase student motivation to learn, this study suggests that the appearance and attire of the professor can have a positive impact on the students' own described behavior. Further, the results of the present study show that this favorable attitude has a broader carryover effect and leaves 
students with a more positive perception of the professor and the course. Most faculty recognize the importance of professionalism to their own success but may not be aware of its perceived importance to their own students who will soon seek to make their own mark in their chosen professions. It has been documented that attire has communicative power and that nonverbal messages may be much more powerful than the spoken word. As educators strive to foster and encourage student learning it is imperative to be cognizant that content is not all that is important.

\begin{tabular}{|c|c|c|c|c|}
\hline \multicolumn{5}{|c|}{$\begin{array}{c}\text { Table } 4 \\
\text { Survey Question Ranking Comparisons }\end{array}$} \\
\hline & \multicolumn{2}{|c|}{ PROFESSIONAL } & \multicolumn{2}{|c|}{ UNPROFESSIONAL } \\
\hline & Mean & Ranking & Mean & Ranking \\
\hline \multicolumn{5}{|l|}{$\begin{array}{r}\text { An Overall Appreciation } \\
\end{array}$} \\
\hline The amount you learn from class. & 2.47 & 11 & 2.76 & 6 \\
\hline Your appreciation for the instructor's effort. & 2.13 & 3 & 2.87 & 12 \\
\hline Your appreciation for the importance of the material. & 2.40 & 8 & 2.79 & 8 \\
\hline Your desire to take additional classes from the instructor. & 2.38 & 6 & 2.91 & 14 \\
\hline Your desire to take additional classes in the subject matter. & 2.59 & 13 & 2.85 & 10 \\
\hline The level of your respect for the instructor. & 1.85 & 1 & 2.85 & 10 \\
\hline \multicolumn{5}{|l|}{ Personal Engagement in the Classroom } \\
\hline Your attentiveness in class. & 2.32 & 4 & 2.76 & 6 \\
\hline Your level of participation in class discussions. & 2.68 & 15 & 2.74 & 5 \\
\hline Your overall attendance for the class. & 2.42 & 9 & 2.62 & 1 \\
\hline Your willingness to ask the instructor questions during class. & 2.67 & 14 & 2.69 & 2 \\
\hline \multicolumn{5}{|l|}{ Out of Class Engagement } \\
\hline The level of your preparation for each class session. & 2.32 & 4 & 2.87 & 12 \\
\hline The amount of time you study for exams and quizzes. & 2.44 & 10 & 2.72 & 3 \\
\hline Your willingness to ask the instructor questions outside of class. & 2.58 & 12 & 2.72 & 3 \\
\hline \multicolumn{5}{|l|}{ Overall Evaluation } \\
\hline Your overall evaluation of a course. & 2.38 & 6 & 2.83 & 9 \\
\hline Your overall evaluation of an instructor. & 2.08 & 2 & 2.93 & 15 \\
\hline
\end{tabular}

\section{AUTHOR INFORMATION}

David Carr is an assistant professor of economics at the University of South Dakota's Beacom School of Business. $\mathrm{He}$ received his Ph.D. from the University of Colorado-Boulder. His current research interests include the economics of multinational firms and environmental regulations, the impact of market structure on industry competition, and pedagogical issues. He has published in the American Economic Review and has articles forthcoming in the International Journal of Management and the College Student Journal.

Angeline Lavin is a professor of finance and the director of graduate programs at the University of South Dakota's Beacom School of Business. She received her Ph.D. in finance from the University of Nebraska-Lincoln, and she also holds the Chartered Financial Analyst (CFA) designation. Her current research interests, in addition to pedagogical issues, include the signaling value of independent auditors' opinions, earnings restatements, and exchange traded funds (ETFs). She has published in the Journal of Financial Services Research, the Journal of Economic Education, the Journal of Financial Research, the Journal of Real Estate Finance and Economics, and Financial Practice in Education.

Thomas Davies is a professor of accounting at the University of South Dakota's Beacom School of Business. He received his J.D. from the University of South Dakota School of Law and LL.M. in Taxation from the University of Missouri - Kansas City. He also holds the Certified Public Account (CPA) designation. His current research interests, in addition to pedagogical issues, include tax policy implications and earnings restatements. He has recently published in the Journal of Forensic Accounting, the Journal of Accounting and Finance Research, and the College Student Journal. 


\section{REFERENCES}

1. $\quad$ Astin, A, Engineering Outcomes, Prism, Vol. 3, No. 1, pp. 27-30, 1993.

2. Bassett, R., Effects of Source Attire on Judgments of Credibility, Central States Speech Journal, Vol. 30, pp. 282-285, 1979.

3. Binkley, C., Business Casual: All Business, Never Casual, Wall Street Journal, pp. D1-D5, April 27, 2008.

4. Chickering, A. and Z. Gamson, Seven Principles for Good Practice in Higher Education, American Association for Higher Education Bulletin, Vol. 39, pp. 3-7, 1987.

5. Harris, M., J. James, J. Chavez, M. Fuller, S. Kent, C. Massanari, C. Moor, and F. Walsh, Clothing: Communication, Compliance and Choice, Journal of Applied Psychology, Vol. 13, pp. 88-97, 1983.

6. Kwon, Y. and J. Johnson-Hillery, College Students' Perceptions of Occupational Attributes Based on Formality of Business Attire, Perceptual and Motor Skills, Vol. 87, pp. 987-994, 1998.

7. Leathers, D., Successful Nonverbal Communication, Macmillan, New York, New York, 1992.

8. Lukavsky, J., S. Butler and A. Harden, Perceptions of an Instructor: Dress and Students' Characteristics, Perceptual and Motor Skills, Vol. 81, pp. 231-240, 1995.

9. Mehrabian, A., Communication without Words, Psychology Today, Vol. 2, No. 4, pp. 53-55, 1968.

10. Molloy, J. Dress for Success Warner Books, New York, New York, 1975.

11. Molloy, J. The Woman's Dress for Success. Follett, Chicago, Illinois 1977.

12. Morris, D., Manwatching: A Field Guide to Human Behavior, Harry N. Abrams, New York, New York, 1977.

13. Rice, D., The Effect of Question-Asking Instruction on Preservice Elementary Science Teachers, Journal of Research in Science Teaching, Vol. 14, No. 4, pp. 353-359, 1977.

14. Rollman, S., How Teachers' Dress Affects Student Opinions, National Enquirer, Vol. 27, November 1977.

15. Rollman, S., Some Effects of Teachers' Style of Dress. Paper presented at the Southern Speech Communication Association Annual Meeting, 1980.

16. Scott, J., J. O'Neal, and C. Cheatham, Nonverbal Communication and Image Building: Their Importance to the Business Professor, Journal of Management Education, Vol. 18, pp. 105-110, 1994.

17. Sebastian, R. and D. Bristwo, Formal or Informal? The Impact of Style of Dress and Forms of Address on Business Students' Perceptions of Professors, Journal of Education for Business, March/April, pp. 196201, 2008.

18. Witcher, A., A. Onquegbuzie, K. Collins, J. Filer, C. Wiedmaier, and C. Moore, Students' Perceptions of Characteristics of Effective College Teachers, 2003. Retrieved from the ERIC Database ED 482517, Microfiche Edition, in November 2007. 
NOTES 